\title{
Musical Improvisational Interactions in the Digital Era
}

\author{
Alessandro Bertinetto
}

\begin{abstract}
This paper considers the issue of musical improvisational interactions in the digital era by pursuing the following three steps. 1) I will raise the question of the meaning and value of liveness, and in particular of live musical improvisation, in the age of the internet and discuss some effects of the socalled digital revolution on improvisation practices. 2) Then I will suggest that the interactions made possible by the web can be understood as kinds of live improvisational practices and I will briefly outline how such practices also involve musical improvisation. 3) Finally, I will focus on some aesthetic and philosophical aspects of new kinds of live improvisation made possible by recent progress in artificial intelligence research.
\end{abstract}

Keywords: Liveness, Improvisation, Internet, Interaction, Artificial Intelligence. 


\section{Sommario}

L'articolo discute la questione delle interazioni dell'improvvisazione musicale nell' era digitale. Articolerò la discussione in tre parti. 1) Anzitutto solleverò la questione del significato e del valore del live, e in particolare dell'improvvisazione musicale dal vivo, nell'era di Internet e discuterò alcuni effetti della cosiddetta rivoluzione digitale sulle pratiche improvvisative. 2) Quindi suggerirò che le interazioni rese possibili dal web possono essere intese come una sorta di improvvisazione dal vivo e descriverò brevemente come tali pratiche coinvolgono anche l'improvvisazione musicale. 3) Infine, mi concentrerò su alcuni aspetti estetici e filosofici di nuovi tipologie di improvvisazione dal vivo rese possibili dai recenti progressi nella ricerca sull'intelligenza artificiale.

Parole chiave: Live, improvvisazione, Internet, interazione, intelligenza artificiale.

\section{Introduction}

The impact of the so-called digital revolution has transformed musical experience just as it has altered other dimensions of human life in the last twenty years (Sidhu, 2016; Lehmann, 2012; Arbo, 2016). The variety and the radical nature of the changes, which are still largely underway, brought by the digital age is on display in the papers of the present and the previous issue of De musica. In my contribution, I intend to offer a sketch of the novelties that the digital era has introduced for a specific musical practice: improvisation. In recent years I have devoted several works to exploring this topic from a philosophical point of view, but I have never directly addressed the issues of how technological innovations have influenced the practice and experience of improvisation and of what the related philosophical questions may be. Here I aim to offer a sketch of how it might be possible to fill this gap. I will do this without going into details, but proposing instead a sort of research project 
concerning three specific subjects.

1) I will raise the question of the meaning and value of liveness, and in particular of live musical improvisation, in the age of the Internet, thereby discussing some effects of the so-called digital revolution on improvisation practices.

2) Then I will suggest that the interactions made possible by the web, which Maurizio Ferraris (2014) has referred to as «total mobilization», can be understood as kinds of live improvisational practices. I will briefly outline how such practices also involve musical improvisational practices.

3) Finally, I will focus on some aesthetic and philosophical aspects of new kinds of live improvisation made possible by recent progress in artificial intelligence research.

The latter is probably the most fascinating aspect of the relationship between improvisational musical practices and new technologies, and it is the theme which I will treat more deeply. In any case, however, I am aware that developing all the mentioned issues adequately is a task that goes beyond the limits of a programmatic article. This essay briefly mentions only aspects of those questions concerning musical improvisation and the digital age that seem to me of particular importance for recent developments of contemporary musical practices and therefore does not claim exhaustiveness.

\section{Live Musical Improvising Through the WWW}

Musical improvisation, as a coincidence of invention and performance, seems fundamentally linked to the immediacy of a "live" experience of music. The possibilities offered by the Internet for musical improvisation therefore seem to be based on some form of "liveness". However, this presents us with a paradox: how can the web present the immediacy of the live experience, if intrinsic to the web is the fact that interaction is remotely and telematically mediated at the global level?

The point is important, but the alleged contrast between the live experience 
and the web is not all that clear. For starters, the meaning itself of the concepts of "live" and "liveness" is far from obvious. Generally speaking, liveness and live seem to imply the direct participation in an event in the space-time circumstances in which the event occurs. However, live performances make massive use of media and take media as models, since media may offer an experience of liveness that, in terms of the feelings of intimacy and proximity it can provide, may be more efficacious than the "real" and "immediate" live itself. The microphone which allows the voice of a songwriter to enter into intimate contact with the listener is already a medium that fits between the ears of the listeners and the voice of the singer, modifying the effect and the acoustic aspect of the latter.

Moreover, as Philip Auslander (2008, p. 35) observes, not only is it true that some live performances are often designed for being mediatized, but the very concept of the live - liveness - is made possible by media reproducibility: the "here and now", the presence, and the spontaneity that are allegedly typical of a live performance experience, are the effects of reproducibility, construction and mediation (Auslander 2008, p. 57). This also explains why we easily apply the concept of liveness to experiences that have nothing to do with the direct contact with the performers in the flesh.

According to Auslander, «[t]he default definition of live performance is that it is the kind of performance in which the performers and the audience are both physically and temporally co-present to one another», but we use the word "live" for very different situations. In reference to radio, television and Internet streaming we speak of live broadcasts although in live broadcasts performers and audiences are only temporally, not spatially, co-present. Moreover, we accept without problems the expression recorded live, which is an oxymoron because in live recordings the audience usually experiences the performance in a different place and time than it occurred. In this case the meaning of liveness is mainly affective: «[L]ive recordings allow the listener a sense of participating in a specific performance and a vicarious relationship to the audience for that performance not accessible through studio 
productions» (Auslander 2008, p. 60).

The Internet has made possible new kinds of liveness. Online or Internet liveness and Group or Social liveness which mean co-presence in the social networks and the connection between groups via smartphones, messenger services, etc. Here liveness is the «sense of always being connected to other people, of continuous, technologically mediated co-presence with others known and unknown» (Auslander 2008, p. 61). Auslander refers to a final type of liveness as internet goes live, which involves real-time interactions with non-human agents.

I shall return later to the issue of the extension of liveness to the interaction with non-human agents in musical improvisational interactions. Now the pressing question is as follows: since the experience of liveness in the musical experience is increasingly achieved through media, is classical liveness, i.e. the temporal and spatial co-presence (in physical terms) of performers and audience, still aesthetically specifically relevant? In other words, does classic liveness have a specific aesthetic value?

I think that in some cases the classic liveness of a musical event i.e. its direct live experience, is not replaceable without a significant loss of aesthetic/artistic contents. Musical improvisation, i.e. the invention of music in the course of a performance, is one of these cases. I do not deny the essential importance of recordings, not only for appreciating repeatedly the outcomes of musical improvisation, but also for making possible improvisational performing styles (cf. Bertinetto 2016, pp. 161-188). However, at least some kinds of musical improvisation seem to be better appreciated live, in the classic sense of the word, that is, by perceiving the unfolding of the event hic et nunc. This is due to the fact that in musical improvisation musicians interact physically with the concrete space-time situation of the performance and what we can call its affective dimension ${ }^{1}$.

\footnotetext{
${ }^{1}$ As we shall see in the next sections the virtual space of an online improvisation is of course concrete as well, However, the possibilities of mutual interaction are different than the
} 
As semiologist of music Eero Tarasti observed, improvisation is deictic, in the sense that the reference to its own situation is part of its ontology: «Improvisation is a trace of a performance situation in the performance itself» (Tarasti 2002, p. 186). Therefore the acousmatic image of improvisation we can derive from a recording is at best a partial experience of the relevant artistic event ${ }^{2}$, since it is deprived of precisely this trace of the performing situation. Of course, for some kinds of improvisation (e.g. a classical jazz improvisation) recordings, far from entailing a significant weakening of their aesthetic qualities, make possible a repeated and enhanced aesthetic experience of this music ${ }^{3}$. But in other cases, in particular in the socalled "free" improvisation performed in the limited space of a club, some aesthetic qualities of the performance require the co-presence among performers and audience in order to be experienced and grasped properly. In these cases, not even video recording can properly convey them, because the possibility of interacting with the performers and with other listeners is indeed an important element of the aesthetic experience of the event of which listeners are a constitutive part. It is not just a question of being able to offer and get acoustic or visual stimuli to and from performers during the performance, but to participate in an artistic event as a social-affective event that involves both performers and audience in emotional and intellectual ways. Even the specific atmosphere of the location can help to properly appreciate the right qualities of the interactive performance that, in some

possibilities available in a physical space, as we are dramatically experiencing using virtual rooms for conferences in the era of Covid-19. I thank Alessandro Arbo for pushing me on this point.

${ }^{2}$ «Acousmatic listening» is the listening of music without perceiving the sources of the sounds that listeners hear. Cf. Hamilton 2003.

${ }^{3}$ Moreover, sometimes a recorded musical improvisation, even independently of the will of its author, can become a musical work in all respects, of which, in addition, various interpretations can be performed. As in the case of Jarrett's Köln concert, of which we can find different interpretations on YouTube. 
cases, recordings cannot reproduce: energy, relaxation, responsiveness, attention, intensity, affective involvement, etc. ${ }^{4}$

Hence, one might think that due to the specific value of the live experience of free improvisational music, the web is, as it were, the enemy of this practice. But this idea would be a mistake. In general, the web seems to increase the psychological desire ${ }^{5}$ and the social offer of live music ${ }^{6}$, in particular - as in the case of experimental and improvised live music - by making possible live musical practices that otherwise could hardly exist. The web acts as a super-archive of musical material and impacts the distribution and sale of material forms of recorded music, but it also «multiplies music's discursive and social mediation» (Born \& Haworth 2018, p. 3), engendering, in the online mode, practices and relations that augment and globalize offline forms of musical practices. In short, it acts as a medium through which offline practices and relations are made possible and enacted. Webpages, social networks, online blogs and webzines not only inform people about the activities of musicians involved in the genre of free improvisation, but they also bring together (online) musicians, audience and critics generating unprecedented possibilities of both online and offline interaction. The web cultural discourses that are generated also intervene in the formation and transformation of musical genres, making possible and constituting artistic practices out of which unprecedented artistic results of different kinds can

\footnotetext{
${ }^{4}$ This is why when listening to recordings of live improvised music, I often realize that in order to fully appreciate the music I should have experienced the event live during its happening. But now it's too late. I elaborated on the impact of the atmospheric location of the musical performance on its aesthetic-expressive features in Bertinetto 2019a.

${ }^{5}$ While revising this paper in Italy in March 2020, during the Covid-19 emergency, I can but confirm this claim. Live concerts are prohibited at the moment and the web is my first musical (re)source: on the one hand, it quenches my thirst for music; on the other, it feeds my desire for live music.

${ }^{6}$ An interesting fact in this regard is the increase in the number of rock and pop music concerts as a consequence of the decrease in CD sales due to the possibility of downloading music and listening to music in streaming (Cf. Auslander 2008).
} 
emerge through both online and offline interactions. Thus, by building online circuits and artistic niches that interact with offline practices, the Internet feeds classic liveness to the extent that without the Internet and its social liveness some musical practices -for example precisely some contemporary genres of musical improvisation- could not have flourished. As my personal experience as a reviewer of new experimental and improvised music for the webzine kathodik (www.kathodik.it) can testify, online music reviews of new musical products (available also online) discursively influence musical practice, contributing to the development of the niche as well as to the articulation of musical genres. Indeed, the Internet has changed the nature of musical objects and of musical genres, producing a continuous mediation between the online and the offline. In practice, the boundary between online and offline is so permeable that, also with reference to the musical experience, the interaction between these two dimensions becomes constitutive of the new live mode in which we live.

Hence, classic liveness is not crushed, but enhanced, by the web. Here is just one significant example: in Berlin the website www.echtzeitmusik.de has served not only a mirror of the activities of musicians involved in the genre of free improvisation, offering information to the audience about concerts and other cultural events, but has also brought together musicians, audience and critics to facilitate creative encounters. The web interacts with a specific offline local situation, mobilizing in the global arena artists, audiences and critics and also making possible a fluid transformation of musical genres and practices. In this case, for example, we witness the generation of a hybrid genre between jazz, neue Musik, hard metal, noise and electronics, which represents the result of the impact of online interactions on the shaping of new musical improvisational practices ${ }^{7}$.

\footnotetext{
${ }^{7}$ On the practices of musical tele-improvisation, or musical improvisation over the Internet, see now Millis 2019. Unfortunately, I had not the opportunity to consult this interesting book for preparing this article, because I discovered it immediately before sending this article to De Musica.
} 


\section{Live Musical Improvisation and Total Mobilization}

I will now briefly address the particular kind of interaction that is established between artists and the audience thanks to the web and, more specifically, I will discuss how critical discourses built and spread by the web affects these interactions. This is not specific of the niche musical genre labelled improvised music: rather, it represents what is happening across a large scale today as part of the digital revolution. Our interactions are not only mediated by the web but are powered by the web and, thus, they feed the web back; put otherwise, they participate in the web. Indeed, as Maurizio Ferraris (2014) suggested, the web itself is not a fixed network, but an ongoing process of weaving $^{8}$. This weaving emerges out of different online and offline interactions that can be understood as total mobilization, as Ferraris calls it.

This total mobilization, I would argue, is the result of ongoing plural improvisational interactions at a global scale. As a matter of fact, it is typical of improvisational interactions that each performance is an evaluation and vice versa each evaluation is a transformative performance. This is what happens with the Internet. Each smartphone or Internet user acts not only a consumer of information, but also as a producer of documents who, through the interaction with other individual and social agents and platforms, generates normativity (i.e. value) and influences on other users' behavior.

This is also what happens in artistic and in musical practices. On the one hand, musicians are engaged in activities of different kind that were once reserved for other professionals. They are not only composers or performers who use apps and tools for generating music and who make use of other music, and abuse of the others' music, as a material to generate new compositions and performances (see Döhl 2016); they are also producers who set up their own record company and distributors of their own music. On the other hand, values, meanings and identities of pieces, albums, styles, genres

\footnotetext{
${ }^{8}$ An interesting application of the weaving metaphor to musical improvisation is elaborate in Schroeder 2014.
} 
and practices emerge out of interactions enacted through and by the web. Thus, the multifarious musical objects distributed on the Internet are continuously subjected to processes of cultural (and sometimes even material) re-elaboration. As in other artistic practices, music witnesses the borrowing of different objects that populate the practice (sounds, patterns, forms, works, recordings, genres, etc.) to become material for a liquid bricolage work (cf. Levy-Strauss 1969) to which authors and listeners, sometimes without awareness, co-participate. The web enables the «near real-time distributed and participatory forms of musical creativity - analogous to the co-present socialities of musical practice and performance» (Born \& Haworth 2018, p. 11).

Therefore, I argue, the dynamics of the cultural mobilization practices generated by and through the web mirror improvisation practices, in which, out of interactions between performers and through the (ab)use of inherited forms and materials (Bertinetto 2018), musical objects are continuously resignified and, in this way, new and sometimes unexpected results emerge. To sum up: musical improvisation is paradigmatic of the interactive practices that give life to the total mobilization of the web age. The transformative emergentist and interactive normativity of improvisation ${ }^{9}$, according to which the meaning and value of the whole performance emerges from and through the contribution of each participant and by virtue of the interaction with the specific performance situation, is exactly the one at play in the interactive online and offline relationships between musicians, listeners and critics, and, more generally, in the global process of weaving which defines the web.

\section{Improvising Live with AI}

As I remarked, digital technology powers classic liveness, making possible live musical practices while mirroring its dynamics. Yet, it generates other

\footnotetext{
${ }^{9}$ For a clarification of the link between emergentism, artistic normativity and improvisation see Bertinetto 2019b.
} 
forms of live music as well.

One of the technological processes that the Internet enables is the telematic production of situational presence (like in online video calls). The situational co-presence, i.e. the fact that the audience is attending the creative process and not only its results, can be enacted through the web, allowing perceivers to virtually enter the spaces of the performance during its staging and vice versa transporting, as it were, performers within the audience's desktops. Thus, the situation of the performance extends its boundaries through cyberspace, beyond performers' physical locations. The ordinary experience of presence - both the presence of the audience directly experiencing the musical, performance and the presence of performers directly interacting with each other - is qualitatively enhanced with a mediatic and interactive copresence $^{10}$. The audience is present at the performance only through the mediation of distance. Performers may be located in different spaces and be co-present to each other only through the interface of the Internet. The aesthetic question in this regard is whether mediatic co-presence allows the audience to grasp the performance's affective and aesthetic atmosphere the same way as the physical presence at a live concert. The answer, I believe, is both yes and no. This kind of interaction made possible by the Internet can produce a strong sense of intimacy and participation: listeners and onlookers may certainly get in close contacts with performers that enter their physical space through the virtual space of the video. Still, even overlooking differences between modalities and objects of sounds perception, mediatic co-presence (between audience and performers as well as between each performer to the others) may not eliminate the feeling that, for better or for worse, the proximity so achieved is only a distant presence, as we may say echoing the title of the performance of the Ethernet Orchestra: Distant

\footnotetext{
${ }^{10}$ This is completely different from the mediation of presence achieved by older media, like radio and tv, that do not allow for the kind of online and offline interaction made possible by the Internet.
} 
Presences ${ }^{11}$. Hence, this experience adds to classic liveness, but does not really replace situational, physical co-presence.

However, there are new musical practices, especially improvisational ones, that extend the scope of classical live improvisation with new kinds of direct co-presence involving interaction with computational performers, i.e. with machines. Here I am referring to:

(a) musical improvisation produced by giving inputs to a machine, or a network of machines like a group of laptops or other devices (for instance smart phones) and

(b) musical interaction between human performers and machines, perhaps both playing traditional musical instruments (say piano, trombone or whatever).

(a) In the first case, computational devices are used as tools manipulated by performers who interact with each other thanks to inputs and outputs digitally generated and processed. Live electronic musical improvisation groups (Musica Elettronica Viva, Nuova Consonanza) that were active from the 1960s to the 1980s and deejays' performances are the pioneers of the practice. But the most interesting example is now offered by Laptop Orchestras: «(...) electroacoustic ensembles of digital instruments such as laptops, tablets, smartphones, and various controllers (... often enriched by other devices...) used to generate or process sound» (Tsabary 2017, p. 1; cf. Le Bouteiller 2020 for a clear outline of this form of musical instrumentality).

Laptop ensembles' improvisation has specific cultural features. In particular, since it is «the product of global, social performance networks» (Tsabary 2017, p. 1), this music is alocal: The cultural roots of these orchestras are multilayered and hybridized and their artistic outcomes are detached from specific cultural contexts. Moreover, this practice enhances traits typical of other musical improvisational practices, in that it blurs the distinctions between composers, performers and instrument designers.

\footnotetext{
${ }^{11}$ Cf. https://www.youtube.com/watch?v=iKL3kzPaSXM. Accessed: January 30, 2021.
} 
From the aesthetic point of view, this practice is quite appealing owing to the fact that practitioners do not rely on learned musical techniques and their activity is highly experimental. Performers interact in real-time by means of copying and modifying each other's code via textual interfaces. Consequently, its most striking aesthetic peculiarity is that, since live coding involves less physical movement and may seem more cerebral and slower, laptop's improvisation is apparently less impactful than other improvisational music $^{12}$. However, although the musical interaction is achieved mainly through aural interchange and enacted by texting and processing codes, this musical improvisation is highly interactional (even when telematic). As a matter of fact, «laptop performers are often faced with new and unpredictable timbres, gestures, textures, and processes improvised by their partners, and they must respond to these sounds and ideas (...)» (Tsabary 2017, p. 2). There are different modalities of interaction. One of the most interesting ones involves assigning the control of one parameter (timbre, rhythm, dynamics, etc.) to each performer, letting the musical outcome emerge out of the interactions of all the improvised parameters. Alternatively, a parameter may be driven by one computer and shared by all laptops ${ }^{13}$. Other interesting cases are the interaction between visual or gestural inputs (like in dance/musical improvisational interactions: cf. CLOrk and Collab'Art de Stéph B's Dancing with Laptops ${ }^{14}$ ), the possibility to convert images into sounds in real-time

\footnotetext{
12 «Performers assess and produce musical ideas through a typed code - a process that naturally takes time (normally 3-30 seconds). Therefore, to maintain the music's drive, live coders often perform metric, loop-based textures, allowing loops to keep playing until the next line of code is evaluated» (Tsabary 2017, p. 2). Performers manipulate signals created by other performers and they can communicate via texting (sometimes displaying codes and texts to the audience). «Laptop musicians are much less dependent than instrumental musicians on gestures and visual cues from their collaborating improvisers, because unlike acoustic instruments, the laptop demands visual focus and is often less immediately responsive» (Tsabary 2017, p. 9).

${ }^{13}$ Cf. youtu.be/liqOkAEEUL0, youtu.be/mRaxFWEA0Qc. Accessed on February 2., 2020.

${ }^{14}$ Cf. youtu.be/1OIzk6Rr14k. Accessed on February 2., 2020.
} 
(BSBLOrk's Holofractal impromptu \#19 part I: Pinheirinh ${ }^{15}$, and orchestral improvisation guided through conduction (cf. CLOrk and CO's Concerto for T-Stick and Two Laptop Orchestras ${ }^{16}$ and CLOrk \& Orchestre Symphonique de l'Isle's Creation for laptop and symphonic orchestras ${ }^{17}$ ).

The unpredictability, and the possible emergence of creative outcomes, is due to the fact that sonic complexity and richness are produced by the interaction among plural performers controlling one device each and not by a unique computer that in principle could replace the web interconnecting the machines. Generally speaking, the effect of this interaction through network technology and shared live coding is the transformation of multiple sources of sounds (the laptops) into a single instrument played by different performers at once. Moreover, the perception of the joint concentration of performers, each one separately absorbed into the dialogue with his own interface, arouses the feeling of attending a sort of ritual ${ }^{18}$.

As this practice shows, a new kind of live improvisational practices -which combines some aspects of the classic live with a form of media co-presenceis made possible by digital technology. Through the web or in a unique spatial location, human beings can improvise musical interactions with each other, as traditional live performers do, but by means of manipulating digital devices. There are important differences between the old and the new practice (among them: differences concerning corporality, telematic interaction, parametric compartmentalization, sonic types, sound control sources and modality, etc.), but the most important ontological and aesthetic features of music improvisation seem to be respected. Improvisers are human beings who

${ }^{15}$ Cf. youtu.be/qAoBlty-q0o. Accessed on February 2., 2020.

${ }^{16}$ Cf. youtu.be/zlheWtLA_-4. Accessed on February 2., 2020.

${ }^{17}$ Cf. youtu.be/qQb4uWWZ34w. Accessed on February 2., 2020.

${ }^{18}$ We may add that every software, tool and code for sounds generating and processing may be put available on the Internet, so that, in a sense, the improvisational interactional works on the long run (i.e. not in the real-time of the performance, but still online) also at the level of performance preparation, learning practice and cultural exchange. 
interact with each other and with the specific situation, musically taking creative decision in the moment of the performance itself, so that the aesthetic quality of the music importantly emerges out of this interaction in real-time. Allowing myself to use and abuse the title of my book on the ontology of musical improvisation (Bertinetto 2016), these musicians perform the unexpected by using the tool of computational technology as a musical instrument.

(b) The second case of technological extension of the classic live music improvisation is philosophically interesting because of its aesthetic and artistic manifestations, and of course also in virtue of its extra-artistic applications. It is not about using artificial intelligence as a controllable tool for generating interactive improvisation, but instead hinges upon playing together with the machine, thus welcoming the machine as a sort of "peer" in a collective improvisation. In other words, human performers (possibly playing any kind of instrument) and computational performers (playing instruments connectable to digital interfaces) interact to produce a live musical improvisation.

The key question is whether a computer, or a robot, is able to improvise. This question hinges on understandings of a computer's creativity. While this is indeed one of the most interesting questions of contemporary scientific research, the literature cannot be surveyed here. The main point, however, is this: if we accept Chomsky's (1964) distinction between rules-governed and rules-changing creativity or Margaret Boden's (1990; 1998) threefold distinction between compositional, exploratory, and transformational creativity, we can say that artificial intelligence can be creative in Chomsky's first sense, as well as in Boden's first and second sense. Machines can improvise using, combining and exploring knowledge acquired and stored, following the rules they are programmed for: for instance, they can recombine melodic and rhythmic patterns and harmonic progressions typical of a certain stylistic environment. Indeed, they use so called genetic algorithms that produce "children" from "parents". Musical material - for example, a 
repertoire of phrases - can be combined to generate other phrases. The results can be complicated by stochastic mutations that produce random variations that can create unexpected effects for listeners, for instance improvising out of key. An example is offered by the improvising robot marimba player Shimon $^{19}$.

Due to its combinatorial and exploratory skills, a computer can "learn" to play on a chords progression or can "learn" to play in the styles of Miles Davis or Mozart, exploring their "conceptual spaces" and solving problems (cf. Casini \& Roccetti 2018, p. 123). Thus, the machine can respond to the inputs of a human co-performer in real-time in relevant and possibly unexpected ways $^{20}$.

Nonetheless, improvisation, properly speaking, cannot be reduced to a combinational and exploratory activity (Young \& Blackwell 2016; Lösel 2018, p. 196). The automatic abilities of adaptation and learning of an algorithm are not such as to be able to bring about its transformation. Machines' memory and speed of data processing are huge, and are enhanced by the connection with other machines (as in the case of the Internet of Things), but without human inputs computers are not able to transform the rules that drive them: they are automatic, not autonomous. A computer on its own can play in a given style, but it cannot carry forward a style. Transformational creativity is not (yet) a possibility for artificial intelligence.

The practice of improvisation requires the ability of evolving while adapting to the environment, and/or while causing the transformation of the environment. And this is what human performers do, when learning how to

\footnotetext{
19 https://www.youtube.com/watch?time_continue=4\&v=FEpQwi0Pgvw. Accessed: January 30, 2021.

20 «The use of a pre-recorded population of phrases (...) evolves [and] allows musical elements from the original phrases to mix with elements of the real-time input to create unique, hybrid, and at times unpredictable, responses for each given input melody. By running the algorithm in real-time, the responses are generated in a musically appropriate time-frame» (Weinberg et al. 2008, p. 353).
} 
improvise in a musical practice (see Bertinetto \& Bertram 2020), which is an exercise that involves the creative generation of habits that leads to shape personal aesthetic styles. Computers cannot improvise in this eminent sense: They cannot develop their know-how out of their own, transforming their "rules of action" by means of adapting one's own doing to a specific situation. Since they can only implement an already functioning algorithm, they don't improvise in the sense of beginning something new - as in Jankélévitch's (1955) view of musical improvisation and in Hannah Arendt's $(1953 ; 1958)$ idea of human action.

When viewed from the biological evolutionist perspective often used in AI research, computers, at the moment at least, cannot be said to evolve without external human intervention. In so-called live algorithms the digital generative algorithm or genotype is produced by a designer and the phenotype (i.e. the offspring of the genotype) may "organically" feedback it, making creative outcomes emerge, only by virtue of inputs given during the computation, i.e. thanks to a direct intervention of the user, who for example provides sounds sampled live (Eldridge 2005; Young \& Blackwell 2016, p. 515). Thus, computational performers alone are not creative emergent systems in which an «environmental feedback can induce structural change and the creation of new primitives» (Eldridge 2005, p. 6). In other words, computational machines cannot improvise in a proactive way, but only in a way that seems proactive (Young \& Blackwell 2016, p. 519). A computational improviser, for example, cannot decide whether a moment of silence is the absence of a performance or a simple pause (Young \& Blackwell 2016, p. 523). Computers, per se, are (still) not entities that can evolve through variations, inheritance and selection: they cannot autonomously adapt themselves to a changing environment, thereby (trans)forming their "habits". So, they are not improvisers properly speaking, since improvisation is precisely this capability of creatively interacting with the environment (including other performers), producing emergent results and transforming habits of behavior. Thus, the sense of agency of a computational performer is 
«achieved by design: musical ideas reside within the system. Rules of behavior, specific actions and responses, control data mapping, and so forth are encodings of ideas that otherwise would be expressed in musical notation or text. So all that is truly occurring, even in a fully improvised context, is that the musician creates input for the computer, which in turn reacts according to rules» (Young \& Blackwell 2016, p. 511) ${ }^{21}$.

Nonetheless, I contend, computational performers do really take part in an improvisational interaction ${ }^{22}$. Algorithms' lack of rules-changing or transformational creativity, i.e. computers' inability to invent the rules of its own performance on the spot, is not a major problem for conceiving of human/computer interactions as improvisational. The algorithm can become a partner of an interactive performance between machines following logical rules and humans making creative decisions (cf. Young \& Blackwell 2016, p. 510). In a musical interaction with a computational improviser, human performers answer to the sounds produced by the algorithm, thereby acknowledging it as a responsive partner, who in turn generates sonic responses that may also contribute to enhance their artistic performance. Unexpected musical events generated by the machine may also extend, enrich and increase the expressive skills of human performers: «a computer can aid an improviser to develop responses and trajectory during a performance» (Dean 2009, p. 139). Thus, the artistic significance of this interaction emerges out through the interaction itself, as in the performance between George Lewis, Jason Moran and the algorithm Voyager the readers can find at this link.

This interaction between humans and machines corresponds exactly to improvisational interactions between human beings. In improvisation, as autopoietic transformational normative interactive open system, meaning and

\footnotetext{
21 As Saint-Gernier (2017) observes, computers proceed by means of algorithms (i.e. by following rules) and chance and this process is clearly not a kind of improvisation.

${ }^{22}$ See Moruzzi (2022) for a short interesting and well-informed discussion of the topic.
} 
value of the process emerge out of multiple interactions and feedback loops between the events produced. Not only the intentions behind the sounds are relevant, but also the way the sounds generated by performer $\mathrm{B}$ performatively assign a sense (a meaning, a value, a direction) to the sounds performed by A, thereby setting an evolving normative frame for assessing the sounds that will produced by $\mathrm{C}$, that in turn will feedback B and A (cf. Bertinetto 2016, pp. 263-294).

Some scholars address the question of computational agency by claiming that computers do not have intention or will, even if their behavior during their musical performance seems intentional. Thus, only a «fictional intentionality» (Lösel 2018) or a «quasi-subjectivity» (Lewis 2017, p. 98) can be attributed to them. This is not the point at hand, however. Intentionality as argued by Elizabeth Anscombe (2000) - is not a matter of finding and ascribing a will as the hidden originator of the actions performed, but of being able to describe the event as an action (or as an interaction) performed by somebody (or something). The event is then to be described not in terms of «This or that happened», but rather in terms of «I do what happened», or «The robot did what happened». So, as suggested by Bagnoli (2010), what matters are not the performers' hidden intentions, but the possibility of ascribing musical events to them, i.e. the possibility of assigning them responsibility and responsiveness. So Lewis (2000, p. 38) is correct in asserting that the point is not «whether machines exhibit personality or identity, but how personalities and identities become articulated through sonic behavior ${ }^{23}$.

In this way, even though the computational performer alone cannot transform its rules and habits of behavior, improvising with a computer is an improvisational interaction. As Lewis elaborates, «improvisational interactions with computational systems produce a kind of virtual sociality

\footnotetext{
${ }^{23}$ In this sense, Eric Lewis (2019, pp. 96-100) argues that computational performers are «fictional improvisers» in which human improvisers engage in an improvisational musical game of make-believe.
} 
that both draws and challenges traditional notions of human interactivity and sociality $[\ldots]$. To improvise is to encounter alternative points of view and to learn from the other; improvising with computers allows us a way to look inside these and other fundamental processes of interaction» (Lewis 2018, pp. $127 \mathrm{f}$.). It is not merely a «simulation of musical experience, but music making itself $-\mathrm{a}$ form of artificial life that produces nonartificial liveness»» (Lewis 2018, p. 128). Thus, all that is needed to produce an artistic improvisational interaction is a musical interactive relationship between human and computational performers, which then results in a collaboration out of which unforeseen outcomes emerge that may be expressively and, more generally, aesthetically valuable. Obviously enough, this kind of improvisation may be experienced directly live; but today, the most popular and widespread way to witness this type of interaction is certainly the Internet, which thus becomes the common scenario of human and computational performers.

\section{Conclusion}

Human/computer collaboration enhances the possibilities of live musical improvisational interaction. When negotiating music through and with machines, human beings interact with the culture that produced the algorithms that are recorded and stored in the machines (Lewis 2000) and thus unprecedented, and possibly creative, outcomes may result. Artistic value, as well as the standards of evaluation themselves, emerge out these interactions: in this sense, normativity is produced improvisationally, as the participants go along with their interaction. Hence, both cases of enhancement of improvisational practices through computers and with computational performers do not lead to the exaltation of computational performers' inhumane capabilities as a precondition for an old-fashioned aesthetics of the machine, but rather integrate technology into humanity's expressive practices (Garnett 2001, p. 32). In so doing, they highlight some important aspects of 
the aesthetics of improvisation.

The aesthetics of improvisation is not an aesthetics of imperfection, but a relational aesthetics of interactivity and of emergence and, as I argued elsewhere (Bertinetto 2012; Bertinetto 2020; Bertinetto 2021), it is paradigmatic for artistic normativity as such. In a musical improvisation, performers interact with a changing environment (including other performers) and the sense of the process in not predetermined by performers' intentions, but results out of interactions that feedback the process driving it autopoietically in unforeseen directions. Analogously, the significance and value of artworks are not hidden in artists' intentions. They emerge out of interactions of different kinds in specific and changing situations: the interactions among the participants to a practice, with the audience, and with critics as well as the interactions with materials, cultural forms, styles, and aesthetic habits and conventions.

As I suggested here, the transformational normativity of improvisation is at work in the fluid interactional experiences generated by the Internet, weaving together offline and online interactions. This also affects the dynamics of artistic practices. In particular, the artistic meaning-transforming interactions among agents and objects that before the age of the Internet were mostly produced in a slower historical time, are now generated in real-time, or in an extended real-time. Far from damaging classic live practices, this new human condition raises them up, enhancing them with artistic practices produced and experienced through and with digital media and computational agents.

\section{References}

ANSCOMBE G.E. M. (2000), Intention, Harvard University Press, Cambridge MA. 
ARBO A. (2016), L'œuvre musicale dans le cyberespace. Implications esthétiques et ontologiques, «Aisthesis», IX, 1, pp. 5-27.

ARENDT H. (1953), Understanding and politics, «Partisan Review», 20, 4, pp. 377-392.

ID. (1958), The Human Condition, University Press, Chicago.

AUSLANDER P. (2008), Liveness: Performance in a Mediatized Culture, Routledge, London and New York.

BAGNOLI C. (2010), Responsability for Action, «Paradigmi», I, pp. 75-86.

BERTINETTO A. (2012), Performing the Unexpected, «Daimon», 57, pp. $61-79$

ID. (2016), Eseguire l'inatteso. Ontologia della musica e improvvisazione, Il Glifo, Roma.

ID. (2018), The Birth of Art from the Spirit of Improvisation, "Quadranti», 6, 1, pp. 119-147.

ID. (2019a), Parker's Mood. Emotional Atmospheres and Musical Expressiveness in Jazz, «Studi di Estetica», XLVII, IV, 2), pp. 23-41.

ID. (2019b), L'emergentismo nell'arte, «Philosophy Kitchen», 11, 7, pp. 177-191.

ID. (2020), Improvisation and the Ontology of Art, «Rivista di Estetica», 73, 1, anno LXI, pp. 10-29.

ID. (2021), Estetica dell'improvvisazione, il Mulino, Bologna.

BERTINETTO A. \& BERTRAM G. (2020), We Make Up the Rules as We Go Along. Improvisation as Essential Aspect of Human Rationality?, «Open Philosophy», 3, 1, pp. 202-221 [https://doi.org/10.1515/opphil2020-0012].

BODEN M. A. (1990), The Creative Mind: Myths and Mechanisms, Basic Books, New York.

ID. (1998), Computing and Creativity. In The Digital Phoenix: How Computers are Changing Philosophy, Blackwell, Oxford.

BORN G. \& HAWORTH C. (2018), From Microsound To Vaporwave: Internet-Mediated Musics, Online methods, and Genre, «Music \& 
Letters», pp. 1-47.

CASINI L. \& ROCCETTI M. (2018), The Impact of AI on the Musical World: Will Musicians Be Obsolete? , «Studi di estetica», XLVI, IV serie, 3, pp. 119-134.

CHOMSKY N. (1964), Current Issues in Linguistic Theory, Mouton, The Hague.

DEAN R. T. (2009), Envisaging Improvisation in Future Computer Music, in R. T Dean (ed.), The Oxford Handbook of Computer music. Oxford, Oxford University Press, pp. 133-147.

DÖHL F. (2016), Mash-up in der Musik, transcript, Bielefeld.

ELDRIDGE A. (2005), Cyborg Dancing: Generative Systems for Man Machine Musical Improvisation, in Proceedings of Third Iteration 2005 (https://www.researchgate.net/profile/Alice_Eldridge/publication/228341 080_Cyborg_dancing_generative_systems_for_manmachine_musical_improvisation/links/00b7d52b312771c074000000/Cyb org-dancing-generative-systems-for-man-machine-musicalimprovisation.pdf).

FERRARIS M. (2014), Total Mobilization, «The Monist», 97, 2, pp. 200-221.

GARNETT G. E. (2001), The Aesthetics of Interactive Computer Music, «Computer Music Journal», 25, pp. 21-33.

HAMILTON A. (2003), The Art of Recording and the Aesthetics of Perfection, in «The British Journal of Aesthetics», 43, 4, pp. 345-362.

JANKELEVITCH V. (1955), De l'improvisation, in La rhapsodie. Verve et improvisation musicale, Flammarion, Paris.

LEHMAN H. (2012), Die digitale Revolution der Musik, Schott Music, Mainz.

LEVY-STRAUSS C. (1969), The Raw and the Cooked (1964), Harper \& Row, New York.

LEWIS E. (2019), Intents and Purposes. Philosophy and the Aesthetics of Improvisation, University of Michigan Press, Ann Arbor.

LEWIS G. E. (2000), Too Many Notes: Computers, Complexity and Culture 
in "Voyager”, «Leonardo Music Journal», 10, p. 33-39.

ID. (2003), The Secret Love between Interactivity and Improvisation, or Missing in Interaction: A Prehistory of Computer Interactivity, in W. Fähndrich (ed.), Improvisation V: 14 Beiträge, Amadeus, Winterthur, pp. 193-203.

ID. (2009), Interactivity and Improvisation, in T. T. Dean (ed.), The Oxford Handbook of Computer Music, Oxford University Press Oxford, pp. 457466.

ID. (2017), From Network Bands to Ubiquitous Computing: Rich Gold and the Social Aesthetics of Interactivity, in G. Born, E. Lewis, W. Straw W. (eds), Improvisation and Social Aesthetics, Duke University Press, Durham, pp. 91-109.

ID. (2018), Why Do We Want Our Computers to Improvise?, in R. T. Dean, A. McLean (eds.), The Oxford Handbook of Algorithmic Music, Oxford University Press, New York.

LEWIS G. E. and PIEKUT B. (eds.) (2016), The Oxford Handbook of Critical Improvisation Studies, 2 Vols., Oxford University Press, New York.

LE BOUTEILLER M. (2020), Des performances musicales par orchestre d'ordinateurs: une instrumentalité nouvelle? - Le cas de PLOrk, in «Musique en acte», 1 pp. XX-XX. [https://gream.unistra.fr/revuemusique-en-acte/musique-en-acte-1-2020/, accessed 22/05/2020].

LÖSEL G. (2018), Can Robots Improvise?, «Liminalities: A Journal of Performance Studies», 14, 1 [http://liminalities.net/14-1/robots.pdf].

MCCORMACK J., ELDRIDGE A., DORIN A., MCILWAIN P. (2009), Generative Algorithms for Making Music: Emergence, Evolution, and Ecosystems, in R. T. Dean (ed.), The Oxford Handbook of computer music, Oxford University Press, Oxford, pp. 354-379.

MILLIS R. (2019), Tele-Improvisation: Intercultural Interaction in the Online Global Music Jam Session, Springer, Cham. 
MORUZZI C. (2022), Improvisation as Creative Performance, in A. Bertinetto \& M. Ruta (eds.), The Routledge Handbook on Philosophy and Improvisation in the Arts, Routledge, London - New York, pp. 47-59.

SAINT-GERMIER P. (2017), Turing ex tempore: un ordinateur peut-il improviser de la musique?, in C. Canonne (ed.), Perspectives philosophiques sur les musiques actuelles, Delatour: Paris, pp. 47-73.

SCHROEDER F. (2014), Soundweaving: Writings on Improvisation: Performing Improvisation - Weaving Fabrics of Social Systems, Cambridge Scholar Publishing, Cambridge.

SIDHU I. (2016). The Digital Revolution, Pearson, Old Tappan NJ.

TARASTI E. (2002), Signs of Music, de Gruyter, Berlin.

TSABARY E. (2017), Improvisation as an Evolutionary Force in LaptopOrchestra Culture, «Critical Studies in Improvisation», 11, 1-2, pp. 1-12.

WEINBERG G., GODFREY M., RAE A., RHOADS J. (2008), A Real-Time Genetic Algorithm in Human-Robot Musical Improvisation, in R. Kronland-Martinet S. Ystad, L. Jensen (eds.), CMMR 2007, LNCS 4969, Springer, Berlin - Heidelberg, pp. 351-359.

YOUNG M., BLACKWELL T. (2016), Live Algorithms for Music: Can Computers Be Improvisers?, in G. E. Lewis and B. Piekut (eds.), The Oxford Handbook of Critical Improvisation Studies, Vol. 2, Oxford University Press, New York, pp. 507-528. 